\title{
Estudo de Viabilidade Técnica e Econômica da Instalação de Sistemas Fotovoltaicos com Armazenamento Auxiliar de Energia
}

\section{Resumo}

Autores: Prof. Dr. Luiz C. P. Silva (PQ), Carlos H.M. Rocha (IC), Augusto C.V. Silva (IC)

Com a crescente preocupação na busca de novas fontes de energia, mais limpas e renováveis, a necessidade de estudos para a implantação desta nova fonte de geração se mostra cada vez mais urgente, este estudo busca concentrar as atenções em sistemas de geração de energia fotovoltaica residenciais, de pequeno porte, já imaginando o cenário de geração distribuída, onde cada consumidor passaria a ter papel ativo no sistema de distribuição de energia, ajudando assim a desafogar o sistema atual, baseado em grandes e centralizadas usinas de geração. Ao concentrar os estudos em sistemas de pequeno porte, este trabalho busca auxiliar na tomada de decisões sobre o investimento neste tipo de sistema, considerando, inclusive, possíveis mudanças na tarifa sobre a energia elétrica, já simulando a cobrança de uma tarifa horária (chamada Tarifa Branca).

Palavras Chave: Geração de Energia, Sistema Fotovoltaico, Armazenamento de Energia.

\section{Introdução}

Desde a crise do petróleo dos anos 70 , o preço da fabricação e instalação de tais sistemas só vem caindo, 0 que só facilita 0 acesso a tecnologia e incentiva a aplicação nos mais variados usos, principalmente residencial, já que é uma energia limpa.

Desta forma, o presente estudo visa analisar a viabilidade técnica e econômica deste tipo de sistema em duas residências na região de Campinas, analisando assim, o potencial de geração de energia e o tempo de retorno do investimento inicial.

Para a análise de viabilidade técnica o estudo se utiliza de simulações feitas pelo software chamado GridLAB-D. Assim, foi possível calcular o payback do sistema com os dados das simulações considerando a possibilidade de venda de energia para a rede em 3 diferentes sistemas tarifários: Tarifa convencional, Tarifa Branca - Sugerida pela ANEEL e Tarifa Branca Utilizada pela CPFL - Paulista.

\section{Resultados e Discussão}

Para 0 estudo foram simuladas duas residências genéricas, uma com um alto consumo mensal de energia e outra com consumo médio.

Com base neste consumo, foram dimensionados sistemas de geração que conseguissem suprir a média desses consumos. Assim, os sistemas compatíveis com cada casa tiveram um custo de $R \$ 114.900$ e $R \$ 52.900$, respectivamente. Também foi realizado o cálculo do tempo de payback considerando um sistema com recurso de controle de descarga da bateria, o qual apenas o faria em horário de ponta, a fim de não utilizar energia da rede quando está estiver no seu valor mais caro. Os tempos de payback para o caso com tarifa vermelha vigente são indicados pela Tabela 1 .
Tabela 1: Tempo de Payback

\begin{tabular}{|c|c|c|c|c|}
\hline \multirow{2}{*}{} & \multicolumn{3}{|c|}{ Tipo de Tarifa de Energia } \\
\cline { 2 - 5 } & $\begin{array}{c}\text { Possui } \\
\text { Controle } \\
\text { de } \\
\text { descarga? }\end{array}$ & $\begin{array}{c}\text { Conven } \\
\text { cio-nal }\end{array}$ & $\begin{array}{c}\text { Branca } \\
\text { - ANEEL }\end{array}$ & $\begin{array}{c}\text { Branca } \\
- \text { CPFL }\end{array}$ \\
\hline $\begin{array}{c}\text { Casa de } \\
\text { consum } \\
\text { o } \\
\text { médio }\end{array}$ & Não & 12 anos & $\begin{array}{c}19,25 \\
\text { anos }\end{array}$ & $\begin{array}{c}13,5 \\
\text { anos }\end{array}$ \\
\cline { 2 - 5 } & Sim & 12 anos & $\begin{array}{c}16,75 \\
\text { anos }\end{array}$ & $\begin{array}{c}12,75 \\
\text { anos }\end{array}$ \\
\hline $\begin{array}{c}\text { Casa de } \\
\text { consum } \\
\text { o Alto }\end{array}$ & Não & $\begin{array}{c}11,5 \\
\text { anos }\end{array}$ & $\begin{array}{c}22,25 \\
\text { anos }\end{array}$ & $\begin{array}{c}13,75 \\
\text { anos }\end{array}$ \\
\cline { 2 - 5 } & Sim & $\begin{array}{c}11,5 \\
\text { anos }\end{array}$ & $\begin{array}{c}15,25 \\
\text { anos }\end{array}$ & 12 anos \\
\hline
\end{tabular}

\section{Conclusões}

Com essa pesquisa foi possível ver que o sistema de energia solar fotovoltaico com armazenamento de energia já é tecnicamente viável, porém possui sérias ressalvas quando observado sob o prisma econômico, o qual tende a se tornar favorável no futuro, graças a medidas de incentivo e também ao constante aumento das tarifas de energia.

\section{Agradecimentos}

Agradeço ao meu orientador, Prof. Dr. Luiz Carlos Pereira da Silva, a UNICAMP, por meio do Serviço de Apoio ao Estudante - SAE por investirem e acreditarem nesta pesquisa.

\footnotetext{
${ }^{1}$ VILLALVA, M. G. ; GAZOLI, J. R. . Energia Solar Fotovoltaica - Conceitos e Aplicações - Sistemas Isolados e Conectados à Rede. 1. ed. São Paulo: Érica, 2012. v. 1. 224p .

${ }^{2}$ Projeto de P\&D ANEEL PA3012 - Aplicação massiva de geração distribuída solar em diferentes tipologias de telhados na cidade de campinas, CPFL- UNICAMP -CNPq.
} 